\title{
Targeting the OB-Folds of Replication Protein A with Small Molecules
}

\author{
Victor J. Anciano Granadillo, ${ }^{1}$ Jennifer N. Earley, ${ }^{1}$ Sarah C. Shuck, ${ }^{1,2,3}$ Millie M. Georgiadis, ${ }^{2}$ \\ Richard W. Fitch, ${ }^{4}$ and John J. Turchi ${ }^{1,2}$ \\ ${ }^{1}$ Department of Medicine/Hematology and Oncology, Indiana University School of Medicine, Joseph E. Walther Hall, R3-C562, \\ 980 W. Walnut Street, Indianapolis, IN 46202, USA \\ ${ }^{2}$ Department of Biochemistry and Molecular Biology, Indiana University School of Medicine, Joseph E. Walther Hall, R3-C562, \\ 980 W. Walnut Street, Indianapolis, IN 46202, USA \\ ${ }^{3}$ Department of Biochemistry, Vanderbilt University School of Medicine, 850 Robinson Research Building, Nashville, TN 37209 , USA \\ ${ }^{4}$ Department of Chemistry and Physics, Indiana State University, Terre Haute, IN 47809, USA
}

Correspondence should be addressed to John J. Turchi, jturchi@iupui.edu

Received 19 August 2010; Accepted 27 September 2010

Academic Editor: Ashis Basu

Copyright (C) 2010 Victor J. Anciano Granadillo et al. This is an open access article distributed under the Creative Commons Attribution License, which permits unrestricted use, distribution, and reproduction in any medium, provided the original work is properly cited.

Replication protein A (RPA) is the main eukaryotic single-strand (ss) DNA-binding protein involved in DNA replication and repair. We have identified and developed two classes of small molecule inhibitors (SMIs) that show in vitro inhibition of the RPA-DNA interaction. We present further characterization of these SMIs with respect to their target binding, mechanism of action, and specificity. Both reversible and irreversible modes of inhibition are observed for the different classes of SMIs with one class found to specifically interact with DNA-binding domains A and B (DBD-A/B) of RPA. In comparison with other oligonucleotide/oligosaccharide binding-fold (OB-fold) containing ssDNA-binding proteins, one class of SMIs displayed specificity for the RPA protein. Together these data demonstrate that the specific targeting of a protein-DNA interaction can be exploited towards interrogating the cellular activity of RPA as well as increasing the efficacy of DNA-damaging chemotherapeutics used in cancer treatment.

\section{Introduction}

Replication protein A (RPA) is an essential protein involved in numerous DNA metabolic pathways including replication, repair, and recombination. RPA's activity in these pathways is in part a function of its single-stranded DNA (ssDNA) binding activity. RPA is a heterotrimeric protein comprised of 70-, 34-, and 14-kDa subunits [1] and binds to DNA through interactions with a series of OB-folds that display a high affinity for ssDNA [2]. OB-folds are found in numerous proteins, specifically those that perform their function through the interaction with single-stranded nucleic acid structures including tRNA synthetases, telomeres, and replication and repair intermediates [3]. The human telomeric DNA-binding proteins, POT1 and TPP1, both use OB-folds to recognize and bind the $3^{\prime}$ ssDNA overhang of telomeres
$[4,5]$. The breast cancer susceptibility protein, BRCA2, has three OB-folds that confer binding to ssDNA, which stimulates RAD51-mediated recombination [6]. The OBfold, also referred to as a Greek key motif [3], consists of two three-stranded antiparallel $\beta$-sheets in which one strand is shared between them, forming a $\beta$-barrel structure. An $\alpha$-helix is typically located between strands 3 and 4 , which packs against the bottom of the $\beta$-barrel [7]. The RPA 70-kDa subunit contains four putative OB-folds, two of which (A and B) comprise the central DNA binding domain (DBD-A/B), which contributes the majority of the ssDNA binding activity of the heterotrimeric protein. While other DNA binding domains within RPA include zinc ribbons and helix-turnhelix motifs [8], the OB-folds of DBD-A/B possess aromatic amino acid residues (F238 and F269 in DBD-A and W361 and F386 in DBD-B) that provide critical base-stacking 
interactions [9]. A recombinant construct containing the DBD-A/B of RPA has been expressed, purified, and shown to be sufficient to bind DNA [9].

The importance of RPA in DNA replication has been demonstrated by genetic studies in yeast [10], genetic knockdown studies in human cells [11] and more recently in chemical genomic studies with an SMI of RPA [12]. RPA plays multiple roles in DNA replication including assembly of prereplication complexes and stabilization of ssDNA following helicase-catalyzed unwinding [13]. Moreover, very recent data demonstrating that RPA can unwind duplex DNA has led to a model where RPA may help in maintaining double-stranded DNA stability throughout replication [14]. Inhibition of any one of these steps is likely to have deleterious effects on DNA replication and ultimately cell viability.

RPA inhibition with a recently identified SMI of RPA, TDRL-505, has been demonstrated to synergize with cisplatin in a human lung cancer cell model [12]. This effect is likely to be a function of alterations in DNA repair, specifically nucleotide excision repair (NER), though effects on homologous recombination cannot be ruled out. Cisplatin [cis-diamminedichloroplatinum (II)) is commonly used as a chemotherapeutic drug in cancer treatment that forms cytotoxic intra- and interstrand DNA-cisplatin adducts. DNA-cisplatin adducts are repaired mainly through the NER pathway, and RPA has been shown to preferentially bind to duplex cisplatin-damaged DNA compared to undamaged DNA through the development of ssDNA [15-17]. RPA is also responsible for the recognition of interstrand cross-links caused by cisplatin treatment $[17,18]$. Cisplatin resistant cancers have been linked to enhanced DNA repair, and thus the ability to impact DNA repair efficiency via modulation of RPA's DNA-binding activity is of potential clinical use to treat cancer in conjunction with platinum agents [19]. Etoposide, a common chemotherapeutic drug that induces replication fork stalling by inhibiting topoisomerase II, was also demonstrated to synergize with the RPA SMI TDRL505 [12]. This synergistic activity is predicted to increase the toxic effects exerted by etoposide both in the context of DNA replication and repair. RPA's role in homologous recombination may be mediating this effect where DNA double-strand breaks are processed to generate a $3^{\prime}$ ssDNA overhang to which RPA binds to help catalyze RAD51dependent strand exchange [20]. In Saccharomyces cerevisiae, mutations within the DNA binding domain and proteinprotein interaction regions of ScRPA lead to highly decreased meiotic recombination [21].

To further investigate the mechanisms of small molecule inhibition of RPA, we have analyzed the in vitro activity of a series of SMIs and their interactions with various RPA constructs. We assessed binding and interaction with full-length heterotrimeric RPA and a construct comprised of just DBD$\mathrm{A} / \mathrm{B}$. The data presented suggest different modes of binding and interactions between the various classes of compounds and RPA, indicating that they potentially target different OB-folds or different regions of the protein structure. We also present data demonstrating that one class of SMIs does appear to have limited specificity; however another class of
SMIs is highly specific for the RPA protein-DNA interaction and does not inhibit the interaction between ssDNA and other OB-fold-containing proteins.

\section{Materials and Methods}

2.1. Materials. Phosphocellulose matrix was obtained from Sigma. Radiolabeled nucleotides were purchased from Perkin-Elmer Life Science (Boston, MA). All oligonucleotide substrates were purchased from Integrated DNA Technology (Coralville, IA) and gel purified by $12 \%$ polyacrylamide, $7 \mathrm{M}$ urea preparative denaturing gel electrophoresis. The 3Pc3 sequence is $5^{\prime}$-GGA GAC CGA AGA GGA AAA GAA GGA GAG AGG-3', the 34-mer is $5^{\prime}$-CTA GAA AGG GGG AAG AAA GGG AAG AGG CCA GAG A-3', and the 15 -mer is $5^{\prime}$ GGT TAC GGT TAC CCC-3'.

2.2. Small Molecule Inhibitors. TDRL-505 was obtained from Exclusive Chemistry (Obninsk, Russia) and CheSS19 was prepared as described in [22]. (+/-) isobornyl haloesters were prepared by the following general procedure. Briefly, to an ice-cooled solution of $(+/-)$-isoborneol (1.00 g, $6.48 \mathrm{mmol})$ in dry $\mathrm{CH}_{2} \mathrm{Cl}_{2}(25 \mathrm{~mL})$ in a Schlenk tube under $\mathrm{N}_{2}$ was added dicyclohexylcarbodiimide $(1.60 \mathrm{~g}, 7.76 \mathrm{mmol})$, followed by the corresponding haloacid $(7.15 \mathrm{mmol})$ and 4-dimethylaminopyridine ( $77 \mathrm{mg}, 0.63 \mathrm{mmol}$ ). The clear colorless solution was stirred 18-24 hours at which time TLC analysis indicated complete consumption of isoborneol (Rf 0.26, 9:1 hexanes/EtOAc), and precipitates of dicyclohexylurea were evident. Diethyl ether $(25 \mathrm{~mL})$ was added, precipitating the bulk of the dicyclohexylurea. The mixture was filtered and the filter cake washed with ether $(2 \times 25 \mathrm{~mL})$. The filtrate which had developed additional precipitate was refiltered and the solvent removed by rotary evaporation. Kugelrohr distillation of the residue afforded the haloesters as colorless oils of greater than $90 \%$ purity. Details concerning the synthesis and chemical characterization of MCI13E and MCI13F are presented in Supplementary Material available online at doi:10.4061/2010/304035.

\subsection{Protein Expression and Purification}

RPA. Human full-length, untagged heterotrimeric RPA (RPA) was purified as previously described in [17].

$D B D-A / B$. The sequence encoding the RPA p70 DNAbinding domains $\mathrm{A}$ and $\mathrm{B}$ was subcloned from the hrRPA plasmid (provided by Dr. Marc Wold, University of Iowa) into the pET15b (Novagen) vector, and the protein was expressed in BL21(DE3) cells (Stratagene) as previously described in [9]. Briefly, cells were grown to an $\mathrm{OD}_{600}$ of 0.8 , induced with $0.5 \mathrm{mM}$ isopropyl-1-thio- $\beta$-Dgalactopyranoside (IPTG) at $37^{\circ} \mathrm{C}$ for $2-3$ hours. Small-scale DBD-A/B preparations were obtained from $1 \mathrm{~L}$ cultures, and, following induction, cells were harvested by centrifugation at $700 \times \mathrm{g}$ for 30 minutes at $4^{\circ} \mathrm{C}$. The pellets were suspended in Buffer A (20 mM Tris, pH 7.5, 10\% glycerol, 500 mM NaCl, 
$10 \mathrm{mM} \beta$-mercaptoethanol (BME), and $1 \mu \mathrm{g} / \mathrm{mL}$ phenylmethanesulfonyl fluoride (PMSF), leupeptin, and pepstatin) at $1 \mathrm{~mL} / \mathrm{gram}$ of cells. The cells were lysed by sonication and insoluble material sedimented at $15,000 \times \mathrm{g}$ for 30 minutes at $4^{\circ} \mathrm{C}$. The supernatant was then loaded onto a $10 \mathrm{~mL}$ phosphocellulose column, equilibrated with Buffer $\mathrm{A}$, and the flow-through material collected. Imidazole was added to the flow-through to a final concentration of $5 \mathrm{mM}$, which was then loaded onto a $2 \mathrm{~mL}$ nickel-NTA-agarose column. The column was then washed with Buffer A containing $50 \mathrm{mM}$ imidazole after which protein was eluted from the column using a gradient from $50-500 \mathrm{mM}$ imidazole. Fractions were analyzed for protein content using Bradford and SDS-PAGE analysis in addition to assessment of DNA binding activity as determined by anisotropy. Fractions containing the DBD$\mathrm{A} / \mathrm{B}$ protein were pooled and dialyzed overnight in Buffer B (1 mM HEPES, pH 7.2, $10 \mathrm{mM}$ dithiothreitol (DTT), $50 \mathrm{mM}$ $\mathrm{NaCl}$, and $1 \mu \mathrm{g} / \mathrm{mL}$ PMSF, pepstatin, and leupeptin) and aliquots stored at $-80^{\circ} \mathrm{C}$.

2.4. Fluorescence Polarization. Fluorescence polarization experiments were preformed as previously described in [23]. Reactions contained $20 \mathrm{nM} \mathrm{F-dT} 12$, and increasing concentrations of RPA and $\mathrm{DBD}-\mathrm{A} / \mathrm{B}$ as indicated in the figure legends. SMIs were diluted in $\mathrm{H} 1$ buffer $(10 \mathrm{mM}$ HEPES, $\mathrm{pH}$ 7.2, $1 \mathrm{mM}$ DTT, $0.01 \% \mathrm{NP}-40$, and $100 \mathrm{mM}$ $\mathrm{NaCl}$ ), and the final DMSO concentration was kept below $1 \%$.

\subsection{Electrophoretic Mobility Shift Assay (EMSA)}

$R P A$ and $D B D-A / B$ Binding. EMSAs were performed as previously described in [16] using a purine rich ssDNA substrate (3Pc3). Briefly, reactions contained $12.5 \mathrm{nM} \mathrm{5'-}$ $\left[{ }^{32} \mathrm{P}\right]$-labeled 3Pc3 ssDNA and the indicated concentrations of RPA or DBD-A/B. Protein was preincubated with the indicated concentration of SMI for 30 minutes at $37^{\circ} \mathrm{C}$. DNA was then added and reactions incubated for additional 5 minutes at room temperature in a final reaction volume of $40 \mu \mathrm{L}$. Reactions were then resolved on a $6 \%$ native polyacrylamide gel and electrophoresed at 170 volts for 1 hour. Gels were dried and quantified via phosphorimager analysis and ImageQuant software (Molecular Dynamics).

E. coli SSB Binding Assay. These EMSAs were performed similarly to those for the RPA constructs, with the following exceptions. Reactions contained $25 \mathrm{nM}$ of $5^{\prime}$-[ $\left.{ }^{32} \mathrm{P}\right]$-labeled 3Pc3 ssDNA and $3.3 \mathrm{nM}$ (assuming homotetramer formation) SSB protein (Enzymatics, Beverly, MA). Reactions $(20 \mu \mathrm{L})$ were carried out in $20 \mathrm{mM}$ HEPES, pH $7.5,1 \mathrm{mM}$ DTT, $0.01 \% \mathrm{NP}-40,100 \mathrm{mM} \mathrm{NaCl}$ and resolved by $6 \%$ native polyacrylamide gel electrophoresis at $25 \mathrm{~mA}$ for 2 hours. Gels were dried and quantified via phosphorimager analysis as described above.

Schizosaccharomyces pombe Pot1(DBD) Binding Assay. EMSAs were performed as described above for EcSSB. Reactions contained $25 \mathrm{nM}$ of $5^{\prime}-\left[{ }^{32} \mathrm{P}\right]$-labeled 15 -mer
ssDNA and $20 \mathrm{nM}$ Pot1(DBD) protein (generously provided by Dr. Deborah Wuttke, University of Colorado, Boulder). Reactions $(20 \mu \mathrm{L})$ were carried out in $20 \mathrm{mM}$ HEPES, $\mathrm{pH}$ 7.5, $1 \mathrm{mM}$ DTT, $0.01 \% \mathrm{NP}-40,100 \mathrm{mM} \mathrm{NaCl}$, at room temperature, and resolved by $6 \%$ native polyacrylamide gel electrophoresis at $25 \mathrm{~mA}$ for 2 hours. Gels were dried and quantified via phosphorimager analysis as described above.

2.6. Analysis of Reversible Inhibition. To assess the reversibility of select SMIs, the indicated SMI was preincubated with $\mathrm{RPA}$ or the DBD-A/B construct for 30 minutes at room temperature. The resulting solution was dialyzed versus $500 \mathrm{~mL}$ $\mathrm{H} 1$ buffer at $4^{\circ} \mathrm{C}$ using $0.5 \mathrm{ml}, 12,000$ molecular weight cut-off dialysis cassettes (Pierce). The resulting protein was recovered and concentration determined by Bradford analysis. Analysis of DNA binding activity was performed either by EMSA or FP. In each series of experiments, there was no loss of DNA binding activity in vehicle controltreated protein.

\section{Results}

3.1. TDRL-505 Targets the Central OB-Folds of RPA. Previous work from our laboratory has identified two classes of RPA SMIs $[12,22,24]$. The first class of SMIs was identified from screening and analysis of structure activity relationships (SARs) of the ChemDiv library [12]. From this analysis, TDRL-505 was identified and contains a substituted dihydropyrazole with a 4-oxo-butanoic acid at N1, a bromophenyl substituent at $\mathrm{C} 3$, and 2-chloro 7-ethoxyquinoline at C5 (Figure 1(a)). Previous in vitro analysis suggested that this SMI was potentially interacting with the central OB-folds found in RPA p70, DBD-A/B, as it was capable of blocking RPA binding to a 12-base ssDNA [12]. RPA binding to this short of DNA substrate is primarily through the DBD-A/B domain. In addition, molecular modeling analysis revealed a thermodynamically favorable interaction between TDRL505 and this domain [12]. DBD-A/B extends from amino acids 181-432. It has been purified and retains DNA binding activity, albeit at approximately $5 \%$ of that observed for the full-length heterotrimer [25]. A similar construct of this region, containing amino acids 181-422, was crystallized in complex with a $(\mathrm{dC})_{8}$ DNA substrate and the structure solved in addition to a DNA-free structure of the 181-432 amino acid region $[26,27]$. In order to examine the effect of TDRL-505 on the DBD-A/B region alone, we subcloned amino acids 181-432 of human RPA p70. The DBD-A/B construct was overexpressed and purified to near homogeneity, via metal affinity chromatography, as determined by SDSPAGE (Figure 2(a)). DNA-binding activity was assessed by EMSA and $125 \mathrm{nM}$ DBD-A/B selected for analysis, which represented approximately 50\% DNA binding of the 34-base DNA substrate (data not shown). Increasing concentrations of TDRL-505 resulted in a concentration-dependent decrease in DNA binding activity as assessed by EMSA (Figure 2(b)). Quantification of the results demonstrates a half-maximal inhibition of approximately $40 \mu \mathrm{M}$ (Figure 2(c)), about twice that observed for the intact heterotrimer [12]. These data 
<smiles>CCOc1ccc2cc(C3CC(c4ccc(Br)cc4)=NN3C(=O)CCC(=O)O)c(Cl)nc2c1</smiles>

(a)

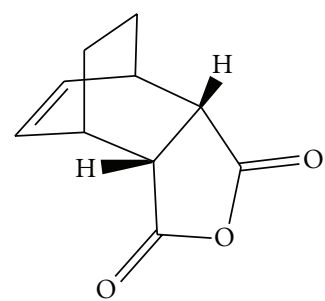

(b)

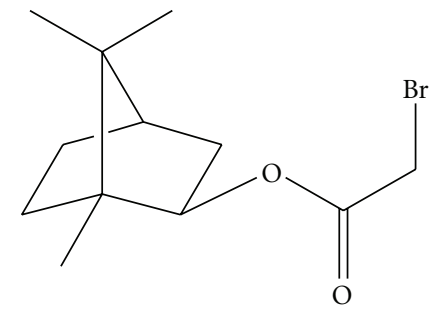

(c)

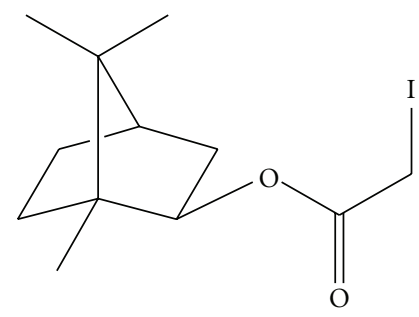

(d)

FIgure 1: Chemical structure of RPA small molecule inhibitors. (a) TDRL-505; (b) CheSS19; (c) MCI13E; (d) MCI13F.

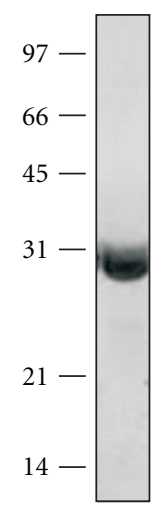

(a)

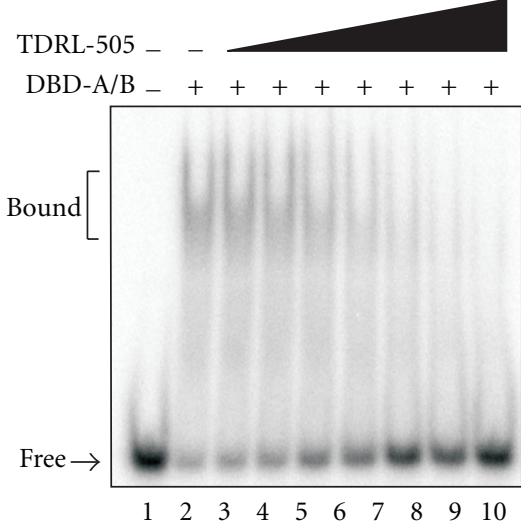

(b)

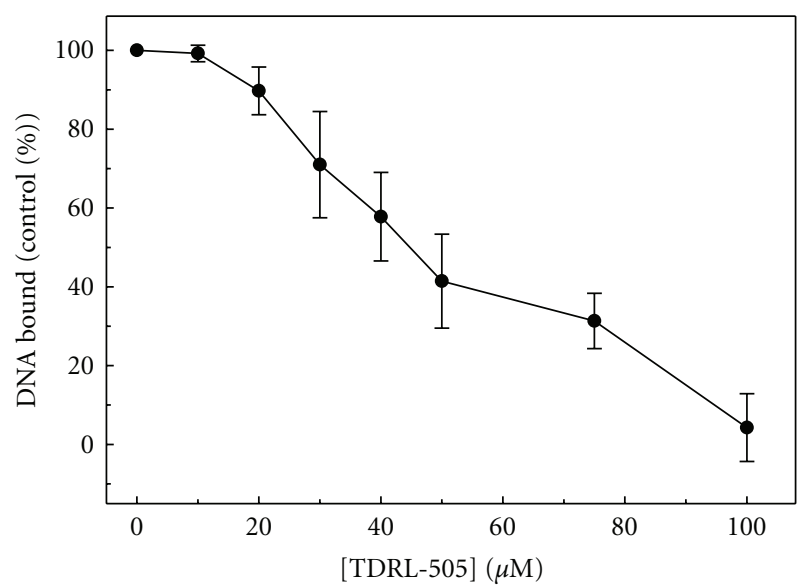

(c)

FIGURe 2: TDRL-505 inhibits RPA DBD-A/B-DNA interactions. (a) SDS-PAGE analysis of purified RPA DBD-A/B. DBD-A/B was purified as described in "Section 2" and analyzed by electrophoresis on a 12\% NuPAGE Bis-Tris Gel. The gel was stained with Coomassie blue. (b) EMSA analysis of TDRL-505 inhibition of DBD-A/B DNA binding activity. Assays were performed as described in "Section 2" with increasing concentrations of TDRL-505 from 10-100 $\mu \mathrm{M}$ in reactions with $12.5 \mathrm{nM}$ DNA and $125 \mathrm{nM}$ DBD-A/B. Products were analyzed by nondenaturing gel electrophoresis, dried, and imaged by phosphorimager analysis. The arrow indicates the position of the free DNA and the bracket the position of the bound DBD-A/B-DNA complex. (c) Quantification of EMSA binding data from Panel (b). The signal representing the RPA-bound and free fractions of DNA was quantified using ImageQuant software, and values represent the mean and SD of triplicate determinations.

support a model whereby TDRL-505 inhibits RPA's DNA binding activity via blocking the protein-DNA interactions at the central OB-folds in RPA p70.

3.2. CheSS19 Inhibits Both WT RPA and RPA AB Region Interactions with DNA. The second class of SMIs we identified contain a bicyclic-isobornyl ester which was initially identified as a hit in a screen of the NCI diversity set and analogs identified in a subsequent screen of the NCI developmental therapeutics general library [24]. Initial SAR analysis indicated that variation in the bridging structure had minimal effects on RPA inhibitory activity while creating reactive anhydrides greatly increased activity [22]. To ascertain if the tricyclic anhydride, CheSS19 (Figure 1(b)), also inhibited DNA binding via an interaction with the central DBD-A/B, we compared its inhibitory activity towards the DBD-A/B construct and full-length heterotrimeric RPA using EMSA 


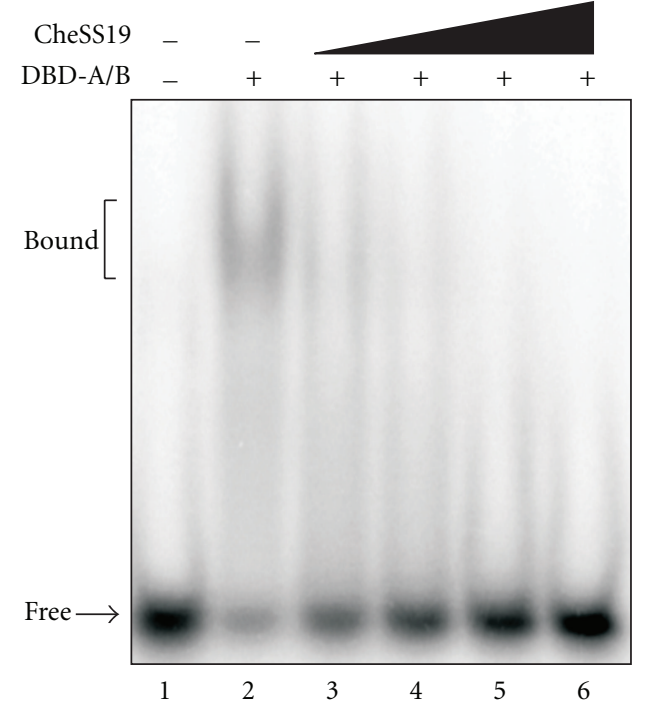

(a)

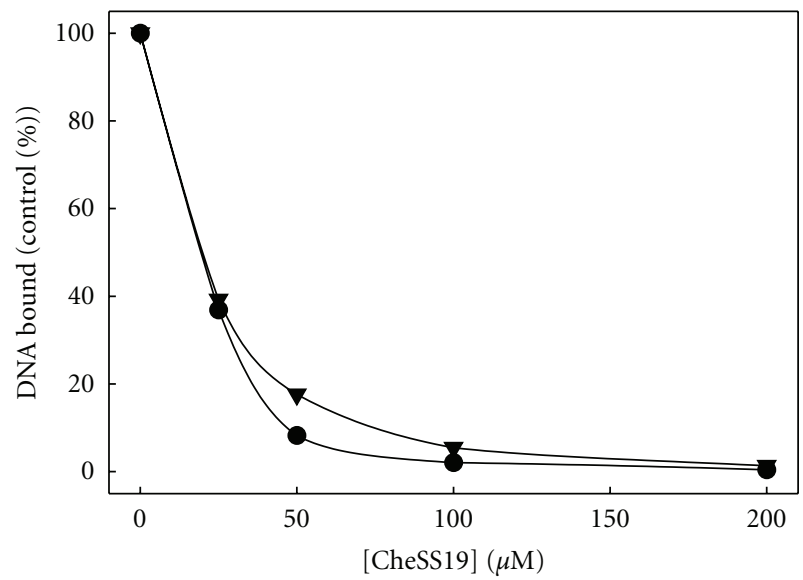

- Full-length RPA

$\nabla \mathrm{DBD}-\mathrm{A} / \mathrm{B}$

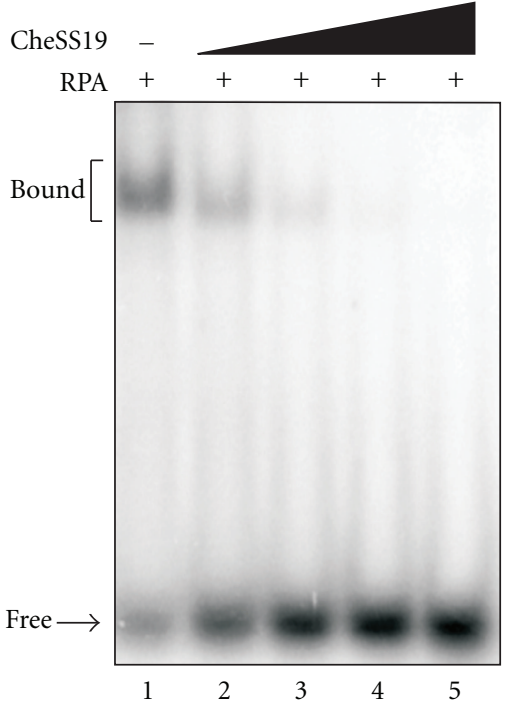

(b)

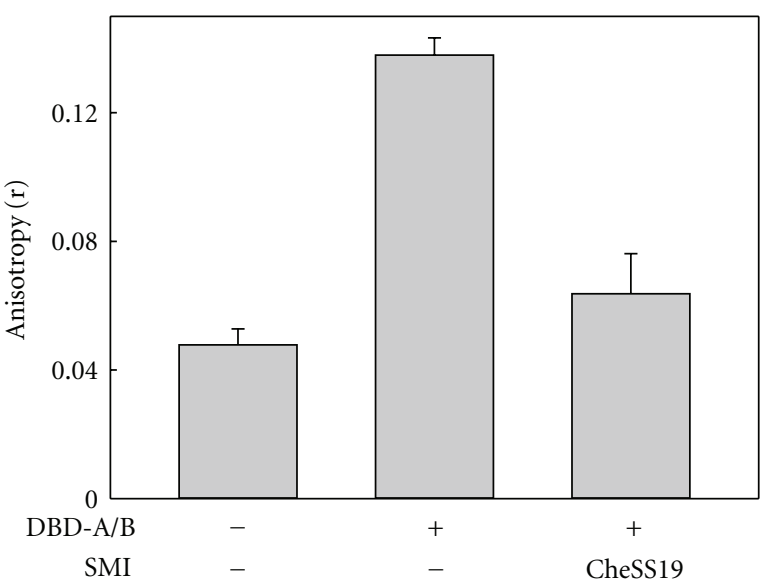

(c)

(d)

FIGURE 3: Irreversible inhibition of RPA DBD-A/B-DNA-binding activity by CheSS19. (a) EMSA analysis of CheSS19 inhibition of RPA DBD-A/B. Assays were performed as described in the legend to Figure 2. Reactions contained $12.5 \mathrm{mM} \mathrm{DNA}, 50 \mathrm{nM}$ DBD-A/B and 0, 25, 50, 100 and $200 \mu \mathrm{M}$ CheSS19 (Lanes, 2-6, resp.) (b) CheSS19 inhibition of full-length heterotrimeric RPA as assessed by EMSA. Reactions were identical to those in panel (a) except contained $25 \mathrm{nM}$ full-length RPA. (c) Quantification of the binding data presented in panels (a) and (b). (d) Fluorescence polarization analysis of CheSS19 inactivated RPA DBD-A/B. RPA DBD-A/B was preincubated with vehicle (1\% DMSO) or CheSS19 ( 1 pmol in $1 \%$ DMSO) for 30 minutes at $37^{\circ} \mathrm{C}$. Following incubation, the reaction mix was dialyzed versus $\mathrm{H} 1$ buffer overnight at $4^{\circ} \mathrm{C}$. The protein was recovered, and DNA-binding activity measured by FP analysis of binding to an F-dT12 substrate was performed as described in "Section 2". Bar 1: DNA control, Bar 2: control vehicle-treated DBD-A/B, and Bar 3: CheSS19-treated DBD-A/B. Control vehicle did not show inhibition of binding before dialysis similarly to Figure 5 Lane 3 . The data represent the mean and range of two independent experiments.

analysis. The results demonstrate that CheSS19 inhibits the DNA binding activity of the DBD-A/B construct with similar potency to the heterotrimeric RPA preparation (Figures 3(a)-3(c)). Our prior observation that CheSS19 irreversibly inhibited full-length RPA prompted us to examine its interaction with the smaller DBD-A/B construct to refine where it covalently binds [22]. In this experiment, DBD$\mathrm{A} / \mathrm{B}$ was incubated with CheSS19 and then the reaction mix dialyzed overnight to remove dissociable inhibitor. Following dialysis, the protein was assessed for binding in a fluorescence polarization assay. Data demonstrates that dialyzed DBDA/B that had been preincubated with CheSS19 was able to inhibit DBD-A/B DNA-binding activity as compared to protein incubated with DMSO vehicle (Figure $3(\mathrm{~d})$ ). These results are consistent with CheSS19 inhibiting DBD-A/B in an irreversible manner. 
3.3. Analysis of Isobornyl Haloesters. While the anhydride groups in the active CheSS series are effective at inhibiting RPA, no cellular activity was observed following treatment with this series of compounds (data not shown). This is potentially a result of the highly reactive anhydride nonspecifically bonding with other components or hydrolyzing to an inactive dicarboxylic acid prior to encountering RPA in the cell nucleus. We therefore employed a less reactive substituent to assess in vitro inhibition and analyzed a series of haloester derivatives of Isobornyl. Synthesis and analysis with the bromo- and iodoesters MCI13E and F, respectively (Figures $1(\mathrm{c})$ and $1(\mathrm{~d})$ ), revealed inhibition of the full-length heterotrimer RPA in EMSA analysis with the iodo-containing compound (MCI13F) being slightly more effective (Figure 4(a)). The isobornyl haloesters, MCI13E and MCI13F, had calculated $\mathrm{IC}_{50}$ of $16.1 \pm 2.8 \mu \mathrm{M}$ and $10.1 \pm 1.0 \mu \mathrm{M}$, respectively. Interestingly, when we assessed inhibition of DBD-A/B, neither MCI13E nor MCI13F compounds inhibited DNA binding of this protein construct (Figure 4(b)). Due to lack of inhibition, the $\mathrm{IC}_{50}$ 's for the inhibition of the DBD-A/B with the isobornyl haloesters were not calculable. Considering the differential inhibition observed between the anhydride and haloesters with respect to specificity, we sought to determine if the isobornyl haloesters inhibited full-length RPA in an irreversible fashion. Full-length RPA was mixed with MCI13E or vehicle control, and then the reaction mixture was dialyzed overnight. Analysis of the resulting protein-DNA complex (Figure 5, lanes 5 and 6) showed that, in reactions where RPA was incubated with MCI13E, inhibition was not reversed by dialysis as would be expected from a reversible inhibitor. In fact, the degree of inhibition was similar to that observed for the MCI13E treated RPA before dialysis (Figure 5, lanes 3 and 4). These results indicate a mode of MCI13E inhibition of RPA that involved a covalent adduct between the MCI13E and RPA. These data suggest that the different chemical reactivity of the isobornyl haloester derivatives alkylate RPA in a different way that likely does not include the DBD-A/B region. Where anhydrides preferentially react with amine residues or hydrolyze in the aqueous medium, alkyl halides are more reactive with sulfur nucleophiles such as Cys residues or hydrogen-bonded $\mathrm{OH}$ groups such as Ser/Thr/Tyr. The isobornyl bromoester has been used previously for labeling cysteines. [28]. Furthermore, analysis of cellular activity revels that, unlike the isobornyl haloesters, the tricyclic anhydride does not display any cellular activity (data not shown).

3.4. SMI Specificity. To determine the specificity of the TDRL-505, CheSS19, and MCI13E/F compounds, we examined their effects on two ssDNA-binding proteins which use OB-folds for recognition and binding of ssDNA, E. coli SSB [3], and the Schizosaccharomyces pombe Pot1(DBD) domain [29]. The EcSSB protein is a non-sequence-specific ssDNA binding protein, whereas the $S p \operatorname{Pot} 1(\mathrm{DBD})$ protein is a telomere-specific, ssDNA binding protein. In these experiments, protein was preincubated with the SMIs, as was done for the RPA experiments, prior to addition of radiolabeled ssDNA to the reactions. TDRL-505 was shown to be ineffective in blocking EcSSB binding to a ssDNA substrate (Figures $6(\mathrm{a})$ and $6(\mathrm{~b})$ ). While there is a slight decrease $(\sim 20 \%)$ in binding observed at the highest concentration of TDRL-505 tested $(100 \mu \mathrm{M})$, this is minimal compared to the nearly $90 \%$ inhibition observed for RPA [12] and the RPA DBD-A/B (Figure 2). Similarly, EcSSB binding was unaffected by CheSS19 and the MCI13E and MCI13F compounds (Figures 6(d) and 6(e)). In all cases, the $\mathrm{IC}_{50}$ of the compounds examined in relation to $\mathrm{EcSSB}$ binding is greater than $100 \mu \mathrm{M}$.

To further validate the specificity of TDRL-505, we examined its influence on the SpPot1(DBD) construct. The mode of ssDNA binding by $S p P \operatorname{Pot} 1(\mathrm{DBD})$ is quite different compared to that of the hRPA protein; however, they both contain ssDNA-binding domains, which are responsible for the majority of the observed DNA-binding activity of the full-length proteins. The SpPot1(DBD) protein was found to be inhibited by TDRL-505 (Figure 7) with an $\mathrm{IC}_{50}$ of $15.7 \pm 1.6 \mu \mathrm{M}$. Together, these data demonstrate that while the RPA SMIs, CheSS19, and MCI13E/F inhibit the interaction of RPA with ssDNA, TDRL-505 compound seems to inhibit eukaryotic ssDNA-binding OB-fold interactions as demonstrated with two different protein-ssDNA complexes.

\section{Discussion}

The six OB-folds distributed throughout three subunits of RPA have been implicated in numerous aspects of DNA metabolism via RPA DNA binding as well as interactions with other proteins $[11,25]$. Inhibition of DNA binding activity by targeting the OB-folds with SMIs has the potential to provide a separation of function and elucidate the contribution of the various domains in the numerous pathways in which RPA participates. Thus, targeting a particular OBfold or other interaction domain may allow for pathwayspecific targeting of RPA. For instance, one could inhibit RPA's activity in nucleotide excision repair (NER) and not in replication, which would present clinical utility in cancer treatment to allow synergy with DNA damaging chemotherapeutic agents while potentially limiting toxicity. It has been suggested that the OB-folds beyond the DBD-A/B region contribute to full-length RPA's ssDNA interaction, which stems from the observation that while $\mathrm{DBD}-\mathrm{A} / \mathrm{B}$ can accommodate a $(\mathrm{dC})_{8}$ DNA substrate, variations in binding are observed dependent on DNA sequence length [1]. Our observation that TDRL-505 can inhibit the DBD-A/B region of RPA p70 from binding to ssDNA supports our previously published molecular modeling data, in which energetically favorable binding was observed within DBD-A and DBD-B as well as the interdomain region [12].

We have further demonstrated that, while not an RPA-specific inhibitor, TDRL-505 displays specificity for eukaryotic ssDNA binding activity of OB-fold containing proteins as no significant inhibition of the related ssDNA binding protein, EcSSB, was observed. Although the EcSSB and $S p$ Pot1(DBD) proteins contain OB-folds, and in this regard, are structurally related to full-length RPA p70 and the $\mathrm{DBD}-\mathrm{A} / \mathrm{B}$, the mechanism of ssDNA binding by these proteins is very different. As shown in Figure 8(a), the 


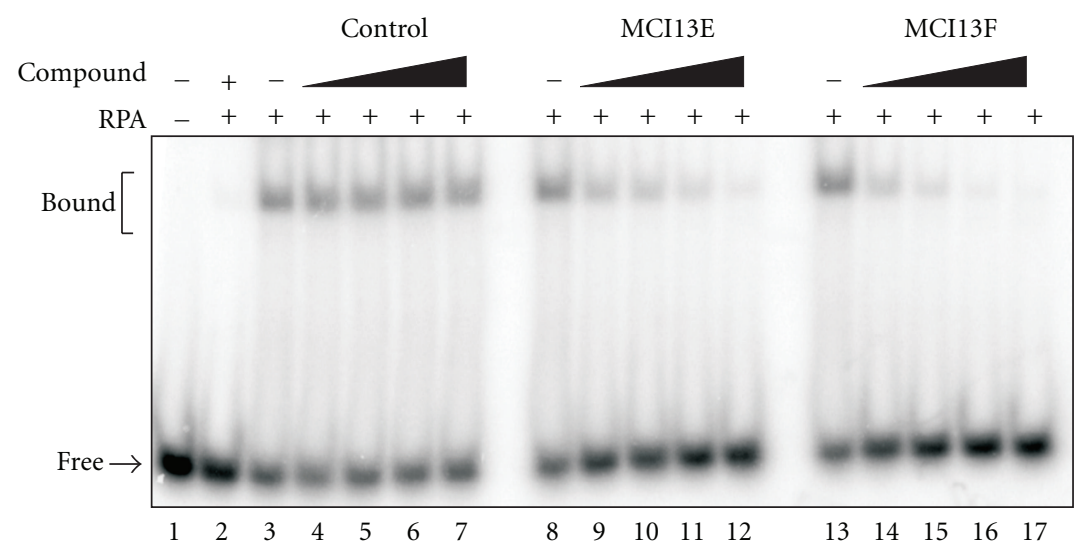

(a)
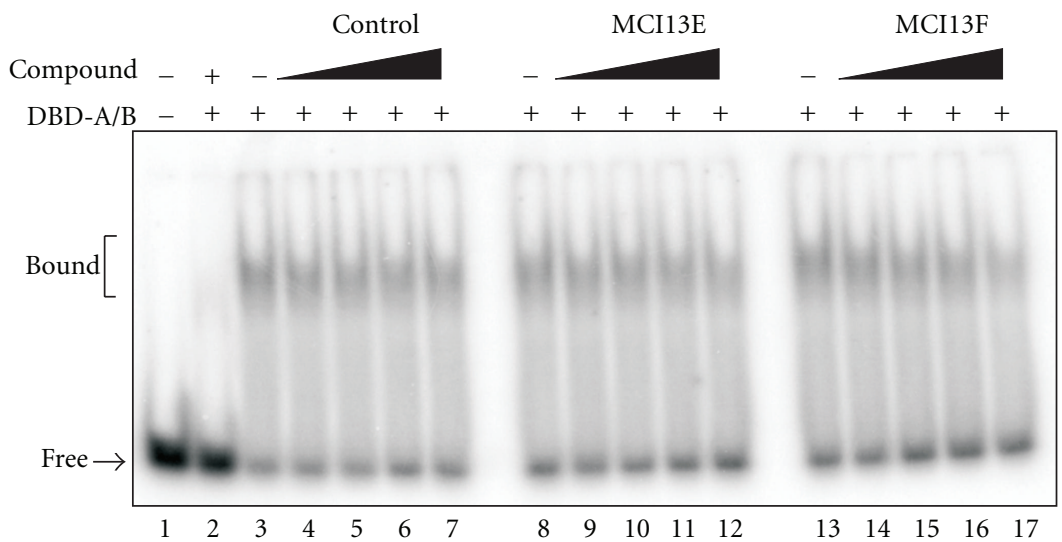

(b)

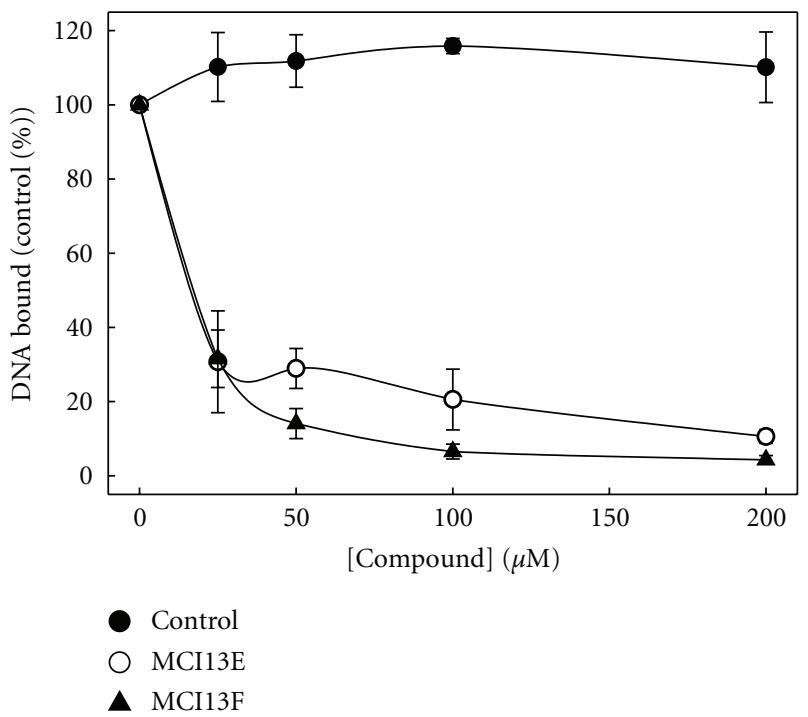

(c)

FIGURE 4: Inhibition of full-length heterotrimeric RPA but not DBD-A/B-DNA-binding activity by the MCI13 series of bicyclic isoborneol haloesters. The control used is a distillate of the reaction components of the synthesis of the MCI13 compounds diluted in equal concentration of DMSO as the MCI13, inhibitors. (a) Increasing concentrations of control compound, MCI13E, or MCI13F (25, 50, 100, and $200 \mu \mathrm{M}$ ) were titrated in DNA binding reactions containing full-length heterotrimeric RPA. Binding to [ $\left.{ }^{32} \mathrm{P}\right]$-ss 30-base 3Pc3 DNA was assessed by EMSA as described in "Section 2." (b) The same inhibitor concentrations were assessed in reactions measuring the binding of DBD-A/B to a 30-mer substrate. (c) Analysis of control, MCI13E, and MCI13F inhibition of full length RPA. Average of three independent experiments is shown with Standard Deviation as error bars. From this graph, $\mathrm{IC}_{50}$ were calculated. MCI13E had a calculated IC 50 of $16.06 \pm 2.78 \mu \mathrm{M}$, while MCI13F had a calculated $\mathrm{IC}_{50}$ of $10.11 \pm 1.0 \mu \mathrm{M}$. 


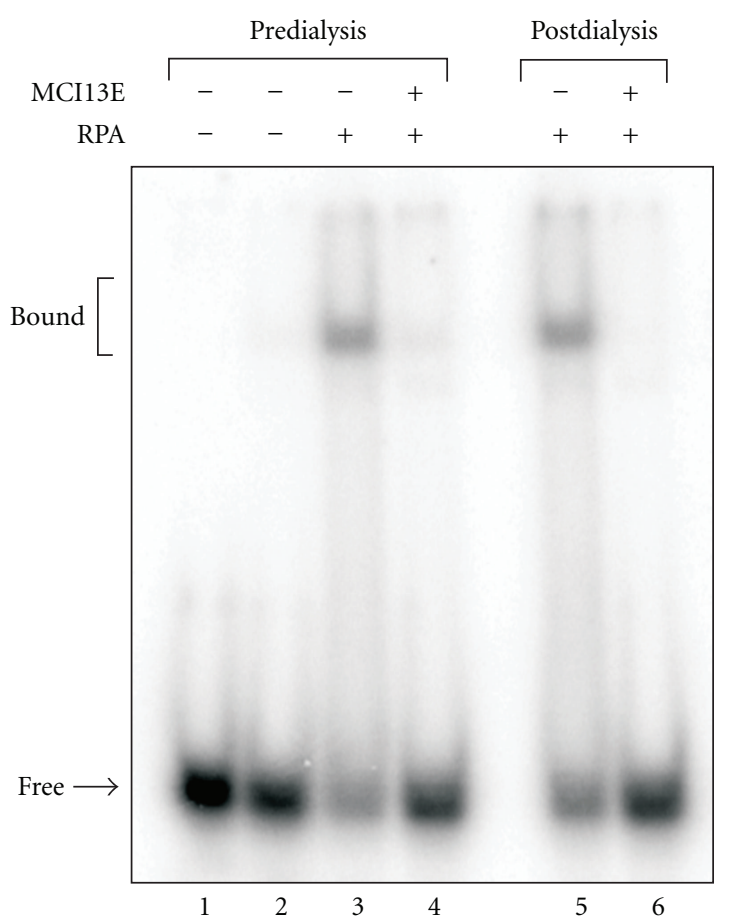

FIGURE 5: Irreversible inactivation of full-length heterotrimeric RPA by MCI13E. Incubation of RPA with MCI13E, dialysis, and recovery were performed as described in the legend to Figure 3. DNA binding activity of the resulting protein was assessed by EMSA using a $5^{\prime}-\left[{ }^{32} \mathrm{P}\right]$-ss 34-base DNA as described in "Section 2." Lanes 1-4 predialysis, lanes 5 and 6 postdialysis.

EcSSB protein contains a single OB-fold, yet, forms a homotetramer yielding a functional molecule containing four OB-folds. The EcSSB protein also has been shown to bind nucleic acid in the reverse polarity compared to RPA [3]. On the other hand, the ssDNA-binding modes of RPA and SpPot1 are more similar. With this in mind, our demonstration that TDRL-505 displays inhibitory effects on both RPA and $S p$ Pot1(DBD) is not surprising. However, if the affinity of TDRL-505 was achieved through the common structural elements of OB-folds, specificity of the inhibitor would be less likely. The SpPot1(DBD) construct has been biochemically characterized and, by analogy to hPot1, binds ssDNA with the same $5^{\prime}$ to $3^{\prime}$ polarity as RPA p70 [30]. Structurally, residues 1-187 have been shown to contain an OB-fold, and residues 188-389 have been postulated to contain a second OB-fold, similar to the hPot1 protein [4] and the RPA DBD-A/B construct. Although ssDNA-binding interactions are mediated by similar structural elements within each OB-fold domain in these proteins, the resulting complexes differ significantly in the overall trajectory of the ssDNA on the surface of the protein and the specific hydrophobic stacking interactions of aromatic residues in the protein with the bases of the ssDNA (Figure 8 ). Thus, as each of the proteins presents a distinct binding site for ssDNA, the specificity of TDRL-505 seems to be limited relative to the other SMIs tested (CheSS19 and MCI13E/F) for inhibition of RPA as compared to other OB-fold-related proteins. Despite the limited specificity, it would appear that TDRL-505 may be specific to eukaryotic OB-fold-ssDNA interactions as it fails to inhibit the EcSSB-ssDNA interaction.

The series of compounds based on a bicyclic framework (MCI13E, MCI13F, and CheSS19) showed inhibition of fulllength heterotrimeric RPA. Interestingly the less reactive derivatives containing a haloester (MCI13E and F) displayed no inhibitory activity in DNA binding assays with purified $\mathrm{DBD}-\mathrm{A} / \mathrm{B}$ while the more reactive tricyclic anhydride derivative, CheSS19, showed potent inhibitory activity against both full-length RPA and the DBD-A/B construct. The mode of RPA inhibition with the tricyclic anhydride and isoborneol derivatives was found to be irreversible, consistent with the reactive anhydride and haloester functional groups. None of the isoborneol compounds were found to significantly inhibit the ssDNA binding activity of EcSSB suggesting that this class of compounds is specific for RPA. Together these data provide evidence suggestive of specific targeting of different functional domains of RPA that can be used to exploit and interrogate their importance in the various metabolic pathways in which RPA participates. Previous data demonstrated that inhibition of RPA with SMIs results in cell cycle arrest and sensitization to DNA-damaging agents, cisplatin and etoposide [12]. These data suggest that exploitation of this chemical genetic approach can ultimately aid in the elucidation of the mechanism of RPA action in critical DNA metabolic pathways including DNA replication, recombination, and repair.

\section{Conclusions}

Small molecule inhibitors have proved to be invaluable in the interrogation of biochemical pathways, protein activity, and cellular function. While targeting macromolecular proteinprotein and protein-DNA interactions is somewhat more complex than targeting an enzyme-substrate interaction, recent work has yielded some success in this regard [12, 32-34]. In this paper, we provide evidence for TDRL-505 inhibition of RPA-DNA binding via an interaction with the central OB-folds of RPA p70, DBD-A/B. This mechanism of inhibition is likely to impact all DNA metabolic events where RPA exerts its activity by high affinity binding to ssDNA. The demonstration that MCI13E and MCI13F do not inhibit the DBD-A/B construct while showing potent inhibition of the full-length RPA heterotrimer points to other critical interactions between RPA and DNA that are essential for its DNA binding activity. While the elucidation of the specific sites of interaction of each SMI and RPA remains, the irreversible inactivation of full-length RPA by MCI13E provides a potential mechanism to identify the specific amino acids being modified and hence determine the subunit and potential DNA-binding domain targeted by this SMI. The identification of the specific site of TDRL505 interaction within DBD-A/B is being pursued via highresolution structural analyses, and together, will provide a framework for the further elucidation of the mechanisms of inhibition and how this impairment in DNA binding activity influences cellular DNA metabolism. 


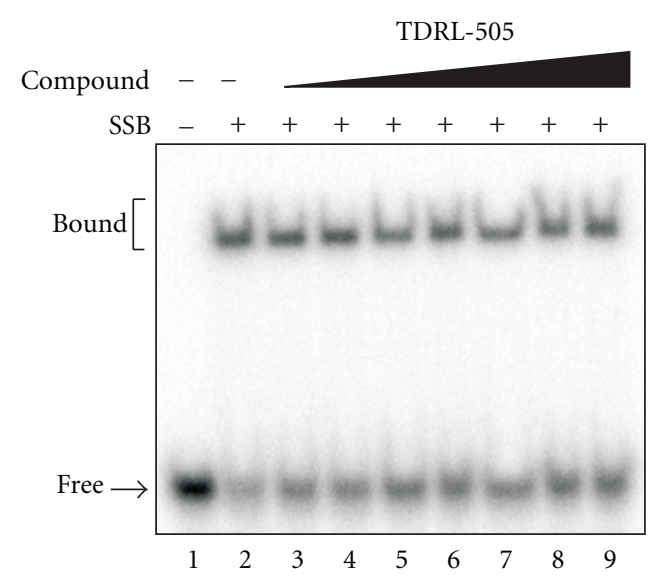

(a)

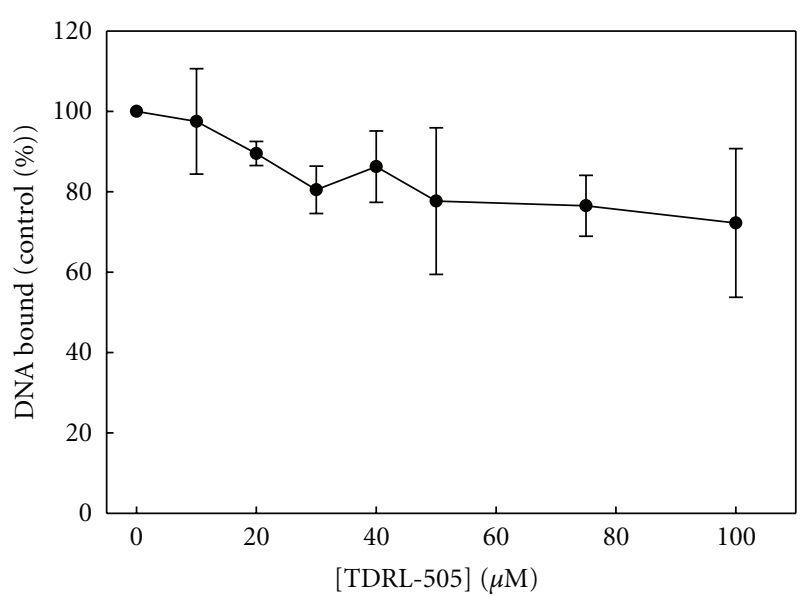

(b)
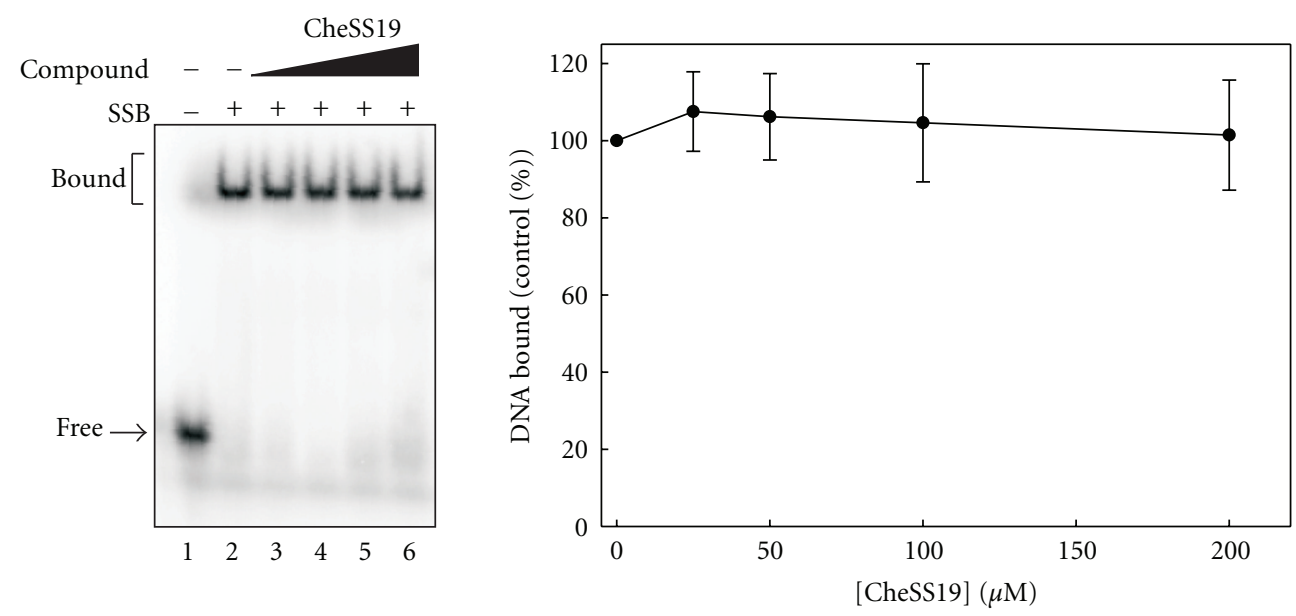

(c)

(d)

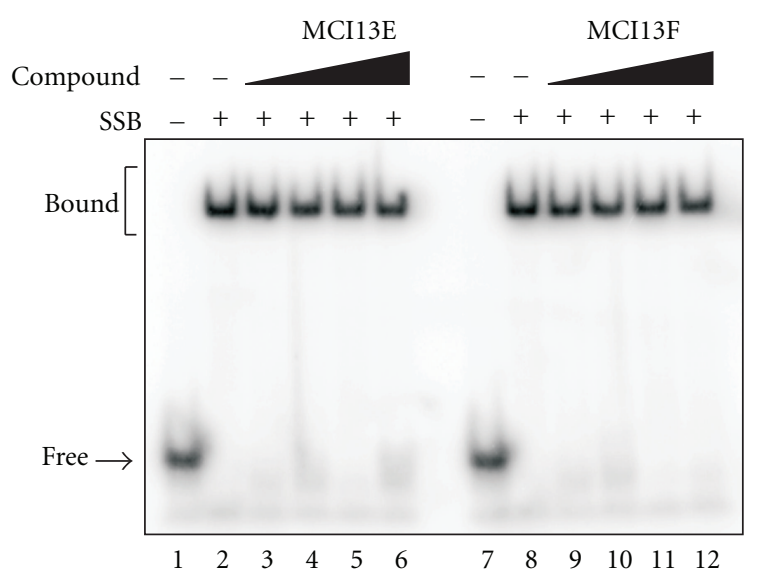

(e)

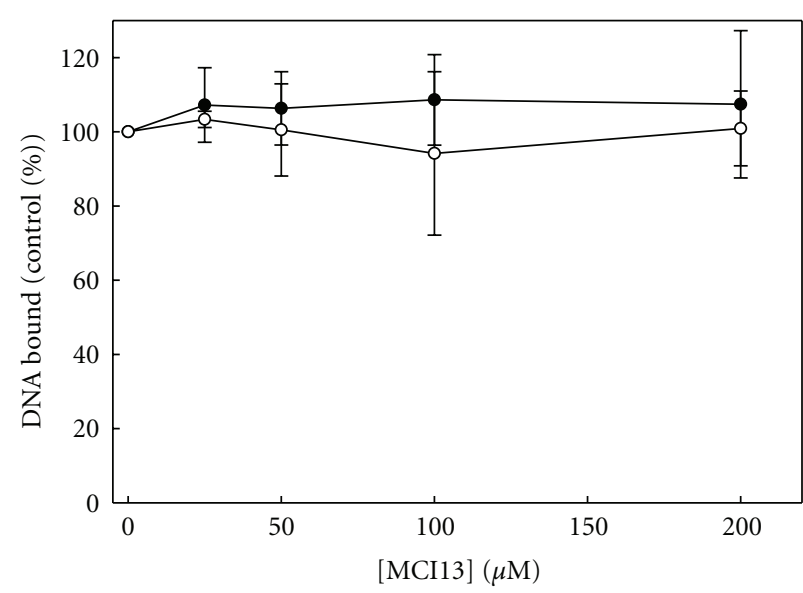

(f)

FIgURe 6: EcSSB protein-ssDNA interaction is not affected by the RPA inhibitors. (a) Titration of TDRL-505 in EcSSB DNA-binding reactions. TDRL-505 $(0,10,20,30,40,50,75$, and $100 \mu \mathrm{M})$ was preincubated with $E c S S B$, and binding to a 30-base pair ssDNA was assessed by EMSA as described in "Section 2." (b) Analysis of TDRL-505 inhibition of EcSSB. The average of three independent experiments is presented with SD. (c) CheSS19 titration in EcSSB DNA-binding reactions. CheSS19 (0, 25, 50, 100, and $200 \mu \mathrm{M})$ was preincubated with EcSSB, and binding reactions were carried out as in (a). (d) Analysis of CheSS19 inhibition of EcSSB. The average of three independent experiments is presented with SD. (e) Titration of MCI13E and MCI13F in EcSSB DNA-binding reactions. Concentrations of MCI13E/F used were 0, 25, 50,100, and $200 \mu \mathrm{M}$. (f) Analysis of MCI13E/F inhibition of EcSSB. The average of three independent experiments is presented with SD. Data for MCI13E is shown as filled circles, and MCI13F is shown as open circles. In panels (a), (c), and (e), the "Free" ssDNA is indicated with an arrow, and the "Bound" ssDNA is indicated by brackets. All reactions were performed in the same order and manner as the RPA-binding reactions. 


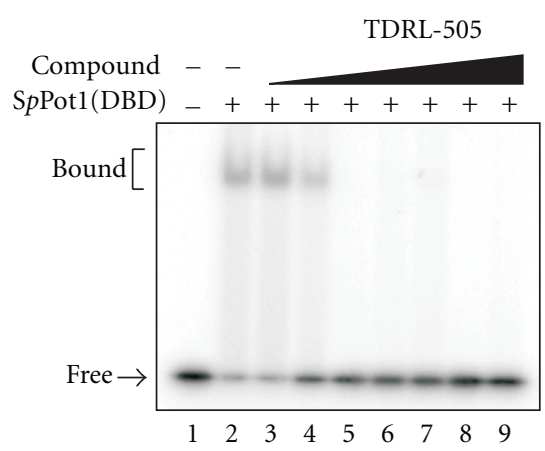

(a)

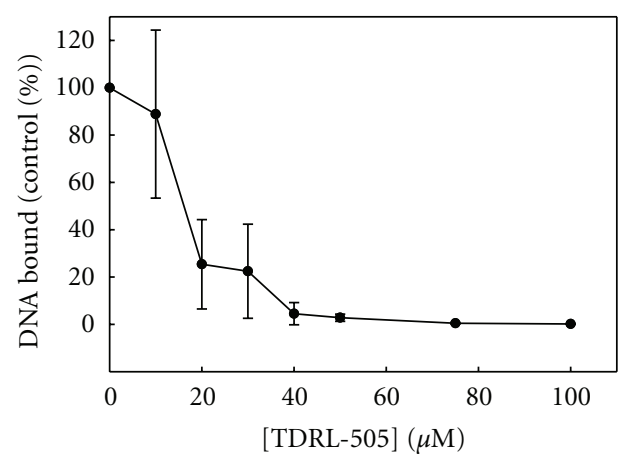

(b)

Figure 7: TDRL-505 inhibits SpPot1(DBD) ssDNA binding. (a) Titration of TDRL-505 in ssDNA-binding reactions with SpPot1(DBD). TDRL-505 was preincubated with $\operatorname{SpPot} 1(\mathrm{DBD})(0,25,50,100 \mu \mathrm{M})$ prior to EMSA analysis of binding to the 15-mer oligonucleotide. "Free" ssDNA is indicated with an arrow, and the "Bound" ssDNA is indicated by a bracket. (b) Analysis of TDRL-505 inhibition of SpPotl(DBD). The average of three independent experiments is presented with SD.

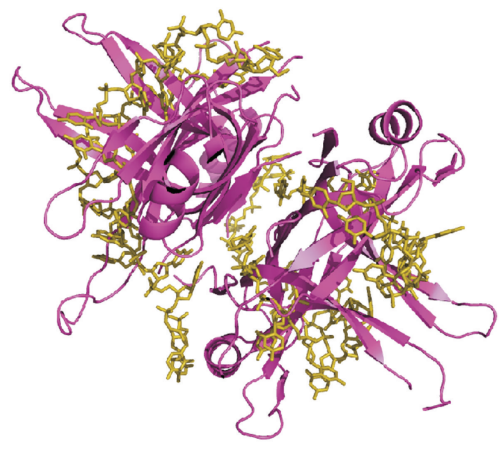

(a)

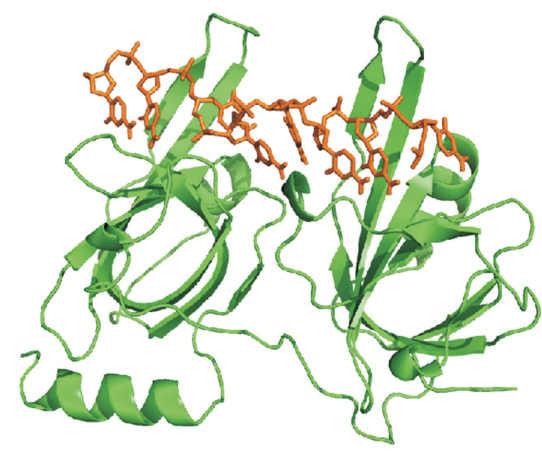

(b)

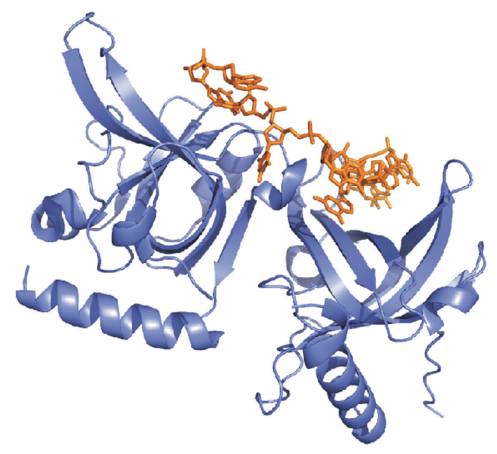

(c)

FIGURE 8: Comparison of the ssDNA-binding interface of OB-fold containing proteins. Proteins are shown as cartoon and ssDNA as stick renderings. (a) Structure of the homotetramer of EcSSB (1EYG); DNA is shown in gold [31]. (b) Structure of the RPA DBD-A/B (1JMC); DNA is shown in orange [27] (c) Structure of the human Pot1(DBD) (1XJV); DNA is shown in orange [4]. Each structure is shown in the same orientation to highlight the different ssDNA binding interfaces used by each of these proteins for their specific functions.

\section{Acknowledgments}

The authors thank all members of the Turchi lab for the helpful discussion and Dr. Deborah Wuttke for providing the $S p$ Pot1(DBD) protein. This paper was supported by NIH award CA082741 to JJT and the National Science Foundation award CHE0521075 for the $400 \mathrm{MHz}$ NMR spectrometer at Indiana State University.

\section{References}

[1] M. S. Wold, "Replication protein A: a heterotrimeric, singlestranded DNA-binding protein required for eukaryotic DNA metabolism," Annual Review of Biochemistry, vol. 66, pp. 6192, 1997.

[2] A. Bochkarev and E. Bochkareva, "From RPA to BRCA2: lessons from single-stranded DNA binding by the OB-fold," Current Opinion in Structural Biology, vol. 14, no. 1, pp. 3642, 2004.

[3] D. L. Theobald, R. M. Mitton-Fry, and D. S. Wuttke, "Nucleic acid recognition by OB-fold proteins," Annual Review of
Biophysics and Biomolecular Structure, vol. 32, pp. 115-133, 2003.

[4] M. Lei, E. R. Podell, and T. R. Cech, "Structure of human POT1 bound to telomeric single-stranded DNA provides a model for chromosome end-protection," Nature Structural \& Molecular Biology, vol. 11, no. 12, pp. 1223-1229, 2004.

[5] F. Wang, E. R. Podell, A. J. Zaug et al., "The POT1-TPP1 telomere complex is a telomerase processivity factor," Nature, vol. 445, no. 7127, pp. 506-510, 2007.

[6] H. Yang, P. D. Jeffrey, J. Miller et al., "BRCA2 function in DNA binding and recombination from a BRCA2-DSS1ssDNA structure," Science, vol. 297, no. 5588, pp. 1837-1848, 2002.

[7] A. G. Murzin, “OB(oligonucleotide/oligosaccharide binding)fold: common structural and functional solution for nonhomologous sequences," EMBO Journal, vol. 12, pp. 861-867, 1993.

[8] E. Bochkareva, S. Korolev, S. P. Lees-Miller, and A. Bochkarev, "Structure of the RPA trimerization core and its role in the multistep DNA-binding mechanism of RPA," EMBO Journal, vol. 21, no. 7, pp. 1855-1863, 2002. 
[9] R. A. Pfuetzner, A. Bochkarev, L. Frappier, and A. M. Edwards, "Replication protein A: characterization and crystallization of the DNA binding domain," Journal of Biological Chemistry, vol. 272, no. 1, pp. 430-434, 1997.

[10] K. Umezu, N. Sugawara, C. Chen, J. E. Haber, and R. D. Kolodner, "Genetic analysis of yeast RPA1 reveals its multiple functions in DNA metabolism," Genetics, vol. 148, no. 3, pp. 989-1005, 1998.

[11] S. J. Haring, A. C. Mason, S. K. Binz, and M. S. Wold, "Cellular functions of human RPA1: multiple roles of domains in replication, repair, and checkpoints," Journal of Biological Chemistry, vol. 283, no. 27, pp. 19095-19111, 2008.

[12] S. C. Shuck and J. J. Turchi, "Targeted inhibition of Replication Protein A reveals cytotoxic activity, synergy with chemotherapeutic DNA-damaging agents, and insight into cellular function," Cancer Research, vol. 70, no. 8, pp. 3189 3198, 2010.

[13] S. Waga and B. Stillman, "The DNA replication fork in eukaryotic cells," Annual Review of Biochemistry, vol. 67, pp. 721-751, 1998.

[14] I. de Vlaminck, I. Vidic, M. T. J. van Loenhout, R. Kanaar, J. H. G. Lebbink, and C. Dekker, "Torsional regulation of hRPAinduced unwinding of double-stranded DNA," Nucleic Acids Research, vol. 38, no. 12, pp. 4133-4142, 2010.

[15] D. B. Zamble, D. Mu, J. T. Reardon, A. Sancar, and S. J. Lippard, "Repair of cisplatin-DNA adducts by the mammalian excision nuclease," Biochemistry, vol. 35, no. 31, pp. 1000410013, 1996.

[16] S. M. Patrick and J. J. Turchi, "Xeroderma pigmentosum complementation group A protein (XPA) modulates RPA-DNA interactions via enhanced complex stability and inhibition of strand separation activity," Journal of Biological Chemistry, vol. 277, no. 18, pp. 16096-16101, 2002.

[17] S. M. Patrick and J. J. Turchi, "Replication protein a (RPA) binding to duplex cisplatin-damaged DNA is mediated through the generation of single-stranded DNA," Journal of Biological Chemistry, vol. 274, no. 21, pp. 14972-14978, 1999.

[18] S. M. Patrick, K. Tillison, and J. M. Horn, "Recognition of cisplatin-DNA interstrand cross-links by replication protein A," Biochemistry, vol. 47, no. 38, pp. 10188-10196, 2008.

[19] E. Reed, "Platinum-DNA adduct, nucleotide excision repair and platinum based anti-cancer chemotherapy," Cancer Treatment Reviews, vol. 24, no. 5, pp. 331-344, 1998.

[20] M. E. Stauffer and W. J. Chazin, "Physical interaction between replication protein A and Rad51 promootes exchange on single-stranded DNA," Journal of Biological Chemistry, vol. 279, no. 24, pp. 25638-25645, 2004.

[21] C. Soustelle, M. Vedel, R. Kolodner, and A. Nicolas, "Replication protein $\mathrm{A}$ is required for meiotic recombination in Saccharomyces cerevisiae," Genetics, vol. 161, no. 2, pp. 535$547,2002$.

[22] J. J. Turchi, S. C. Shuck, E. A. Short, and B. J. Andrews, "Targeting nucleotide excision repair as a mechanism to increase cisplatin efficacy," in Platinum and Other Heavy Metal Compounds in Cancer Chemotherapy, A. Bonetti, R. Leone, F. M. Muggia, and S. B. Howell, Eds., Humana Press, New York, NY, USA, 2009.

[23] B. J. Andrews, J. A. Lehman, and J. J. Turchi, "Kinetic analysis of the Ku-DNA binding activity reveals a redox-dependent alteration in protein structure that stimulates dissociation of the Ku-DNA complex," Journal of Biological Chemistry, vol. 281, no. 19, pp. 13596-13603, 2006.
[24] B. J. Andrews and J. J. Turchi, "Development of a highthroughput screen for inhibitors of replication protein A and its role in nucleotide excision repair," Molecular Cancer Therapeutics, vol. 3, no. 4, pp. 385-391, 2004.

[25] I. M. Wyka, K. Dhar, S. K. Binz, and M. S. Wold, "Replication Protein A interactions with DNA: differential binding of the core domains and analysis of the DNA interaction surface," Biochemistry, vol. 42, no. 44, pp. 12909-12918, 2003.

[26] E. Bochkareva, V. Belegu, S. Korolev, and A. Bochkarev, "Structure of the major single-stranded DNA-binding domain of replication protein A suggests a dynamic mechanism for DNA binding," EMBO Journal, vol. 20, no. 3, pp. 612-618, 2001.

[27] A. Bochkarev, R. A. Pfuetzner, A. M. Edwards, and L. Frappier, "Structure of the single-stranded-DNA-binding domain of replication protein A bound to DNA," Nature, vol. 385, no. 6612, pp. 176-181, 1997.

[28] R. I. Murray, I. C. Gunsalus, and K. M. Dus, "Active site studies of cytochrome $\mathrm{P}=450 \mathrm{CAM}$. I. Specific cysteine labeling with the affinity reagent isobornyl bromoacetate as a model for substrate binding," Journal of Biological Chemistry, vol. 257, no. 21, pp. 12517-12525, 1982.

[29] M. Lei, E. R. Podell, P. Baumann, and T. R. Cech, "DNA selfrecognition in the structure of Pot 1 bound to telomeric singlestranded DNA," Nature, vol. 426, no. 6963, pp. 198-202, 2003.

[30] J. E. Croy, E. R. Podell, and D. S. Wuttke, "A new model for schizosaccharomyces pombe telomere recognition: the telomeric single-stranded DNA-binding Activity of Pot11389," Journal of Molecular Biology, vol. 361, no. 1, pp. 80-93, 2006.

[31] S. Raghunathan, A. G. Kozlov, T. M. Lohman, and G. Waksman, "Structure of the heterodimeric complex between CAD domains of CAD and ICAD," Nature Structural Biology, vol. 7, no. 8, pp. 658-662, 2000.

[32] P. Y. Ng, Y. Tang, W. M. Knosp, H. S. Stadler, and J. T. Shaw, "Synthesis of diverse lactam carboxamides leading to the discovery of a new transcription-factor inhibitor," Angewandte Chemie, vol. 46, no. 28, pp. 5352-5355, 2007.

[33] R. E. Moellering, M. Cornejo, T. N. Davis et al., "Direct inhibition of the NOTCH transcription factor complex," Nature, vol. 462, no. 7270, pp. 182-188, 2009.

[34] M. N. Saha, H. Jiang, J. Jayakar, D. Reece, D. R. Branch, and H. Chang, "MDM2 antagonist nutlin plus proteasome inhibitor velcade combination displays a synergistic antimyeloma activity," Cancer Biology and Therapy, vol. 9, no. 11, pp. 937-945, 2010. 

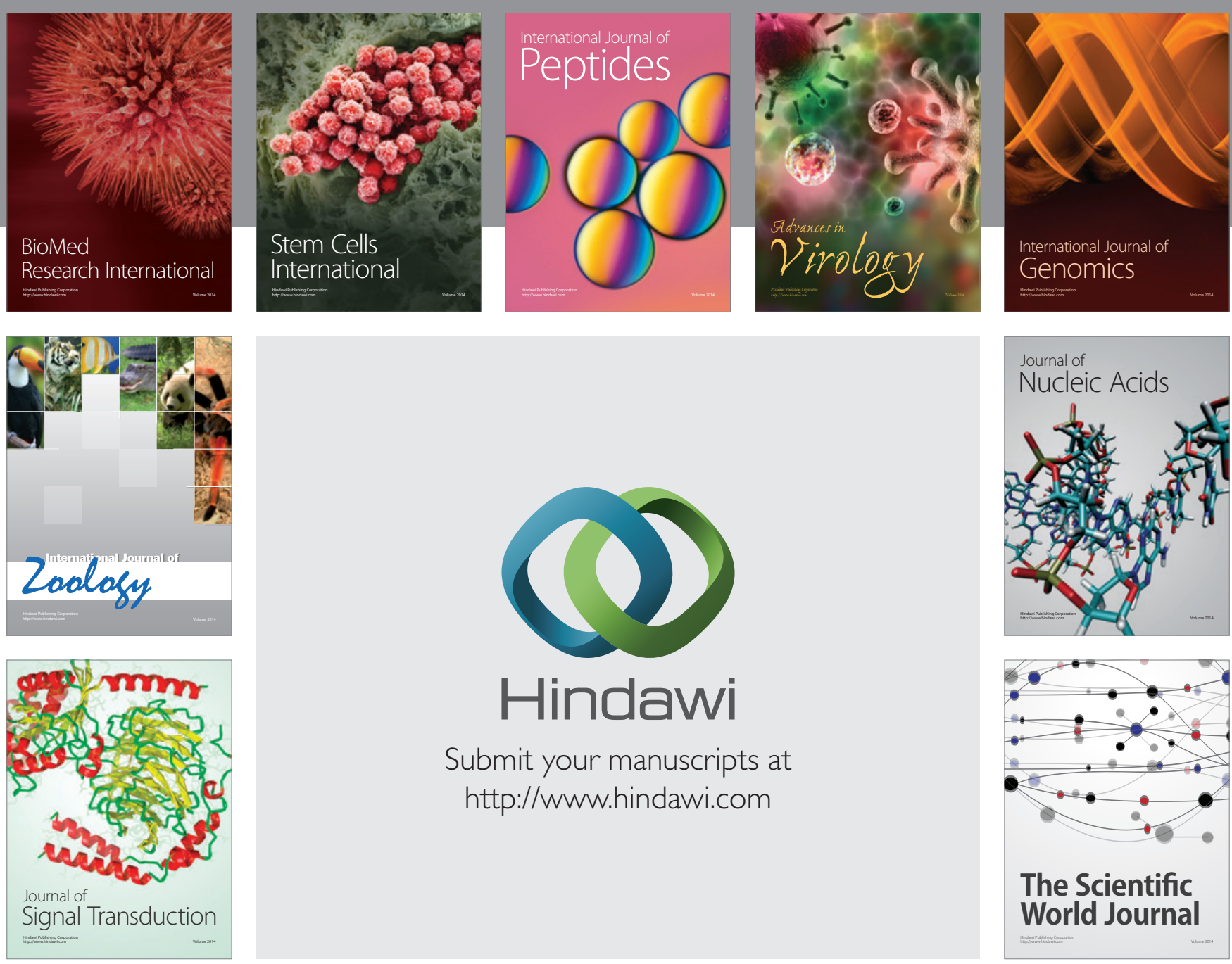

Submit your manuscripts at

http://www.hindawi.com
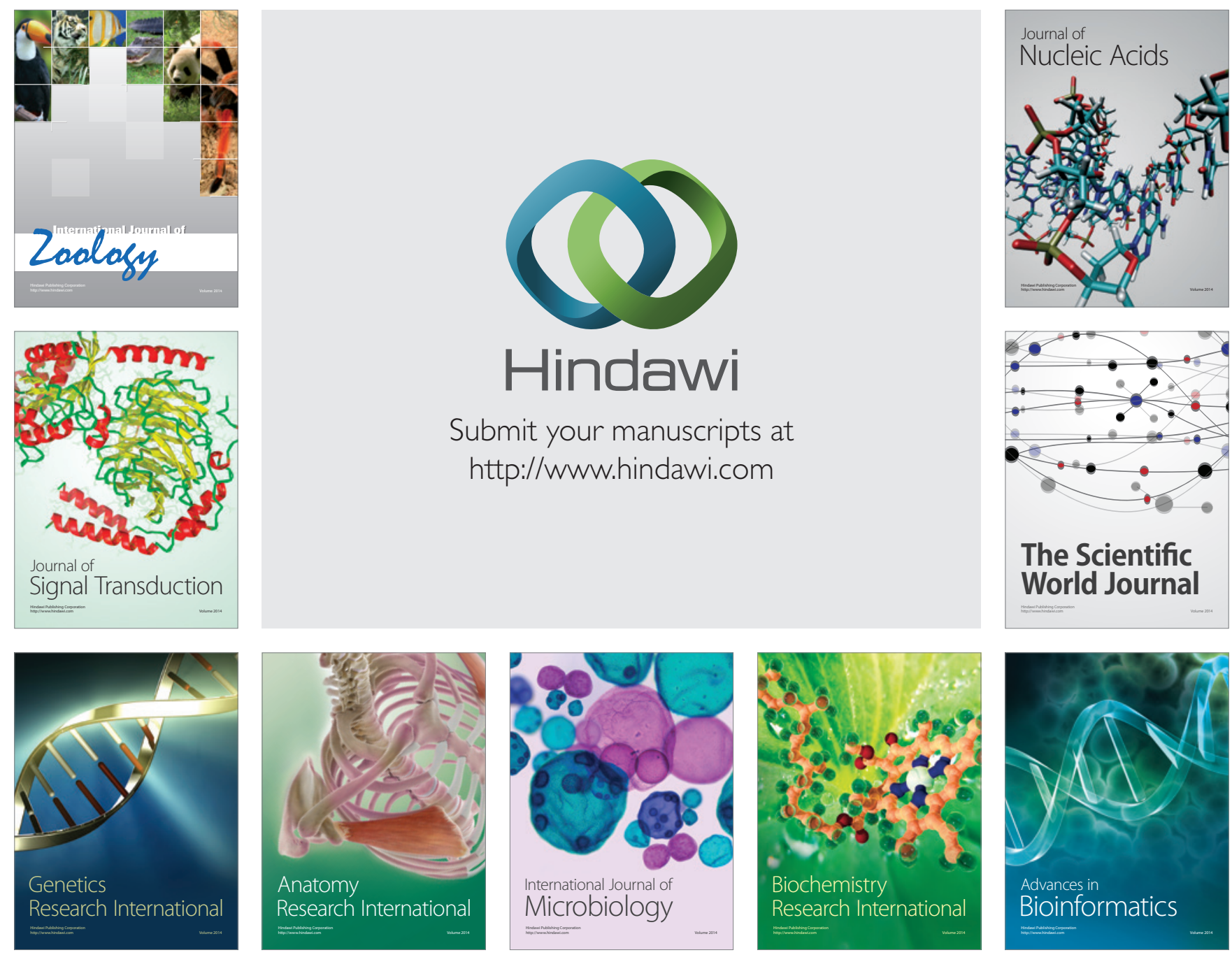

The Scientific World Journal
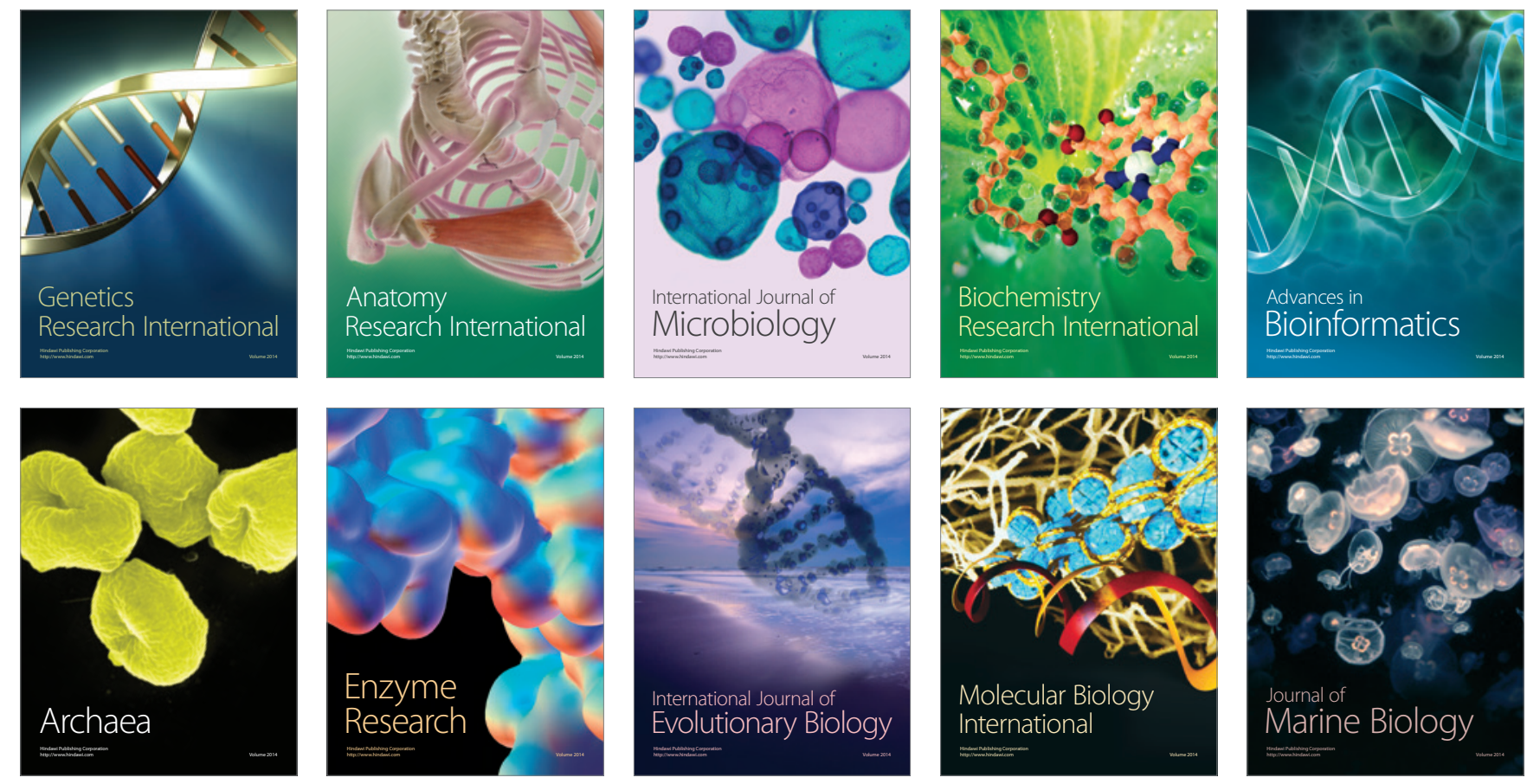